\title{
ARTICLE
}

Received 12 Jun 2012 | Accepted 15 Nov 2012 | Published 18 Dec $2012 \quad$ DOl: 10.1038/ncomms2296

\section{Recent patterns of crop yield growth and stagnation}

\author{
Deepak K. Ray ${ }^{1}$, Navin Ramankutty², Nathaniel D. Mueller ${ }^{1}$, Paul C. West ${ }^{1} \&$ Jonathan A. Foley ${ }^{1}$
}

In the coming decades, continued population growth, rising meat and dairy consumption and expanding biofuel use will dramatically increase the pressure on global agriculture. Even as we face these future burdens, there have been scattered reports of yield stagnation in the world's major cereal crops, including maize, rice and wheat. Here we study data from $\sim 2.5$ million census observations across the globe extending over the period 1961-2008. We examined the trends in crop yields for four key global crops: maize, rice, wheat and soybeans. Although yields continue to increase in many areas, we find that across $24-39 \%$ of maize-, rice-, wheat- and soybean-growing areas, yields either never improve, stagnate or collapse. This result underscores the challenge of meeting increasing global agricultural demands. New investments in underperforming regions, as well as strategies to continue increasing yields in the high-performing areas, are required.

\footnotetext{
${ }^{1}$ Institute on the Environment (IonE), University of Minnesota, St Paul, Minnesota 55108, USA. ${ }^{2}$ Department of Geography and Global Environmental and Climate Change Center, McGill University, Montreal, Quebec H3A 2K6, Canada. Correspondence and requests for materials should be addressed to D.K.R. (email: dray@umn.edu).
} 
$\mathrm{T}$ he global demand for agricultural crops is expected to roughly double by 2050 , driven by increases in population, meat and dairy consumption and biofuel use ${ }^{1-3}$. However, between 1985 and 2005, the total global crop production increased by only $28 \%$ (through a $\sim 2.5 \%$ net expansion of global cropland area, an $\sim 7 \%$ increase in the frequency of harvesting, and an average $\sim 20 \%$ increase in crop yields per hectare $)^{4}$. Clearly, these recent gains in global crop production fall short of the expected demands, leaving us with an important question: Which crops and which geographic regions offer the best hope of meeting projected demands, and where are improvements most needed?

Adding to this concern, some authors have suggested that yields for many important crops may be stagnating in some regions around the world ${ }^{5-10}$. In particular, there are concerns that yields may be stagnating or declining for three key cropsmaize, rice and wheat-which together produce $\sim 57 \%$ of the world's agricultural calories ${ }^{2}$. A slowing, or worse, stagnation or collapse in the yield gains in these crops would have profound implications for the world food system.

Although some authors have already noted some specific localor national-scale examples of where crop yields may have stagnated $^{5-7,10-12}$, no spatially detailed assessment of global crop yield trends has been attempted to date. To consider the current state and trends in yields of the world's four key crops (maize, rice, wheat and soybean) that currently provide $\sim 64 \%$ of agricultural calorie production ${ }^{2}$, we employed new long-term and high-resolution geospatial databases of global agricultural systems ${ }^{13}$, synthesized from $\sim 2.5$ million census observations (Supplementary Note 1, Supplementary Methods, Supplementary Table S1 and Supplementary Figs S1 and S2). Using these data, we analysed detailed spatial and temporal patterns of yields, determining where these four key crops have experienced yield stagnation and where crop yields are still increasing.

These new data give us a dramatically improved understanding of crop yield and area changes across regional and global scales, which are otherwise often obscured using only national census statistics $^{11}$. For example, using only the United Nations Food and Agricultural Organization's national crop statistics ${ }^{14}$ suggests that American wheat yields increased everywhere at $\sim 0.01$ tons $\mathrm{ha}^{-1}$ year ${ }^{-2}$ (0.3\%/year) between 1999 and 2008. Using our new high-resolution geospatial data set, we were able to identify that yields in $\sim 36 \%$ of the American wheat-harvested areas $(\sim 7$ million ha) are not improving; only in the remaining $\sim 64 \%$ of wheat land ( $\sim 13$ million ha) are yields improving, and at different identifiable rates.

Here we analyse changes in yields over time at each of the political units where maize, rice, wheat and soybean were harvested. We find that across $24-39 \%$ of maize, rice, wheat and soybean-growing areas, yields have either never improved, stagnated or collapsed. This result highlights the increasingly difficult challenge of meeting increasing global agricultural demands.

\section{Results}

Global yield trends. We found that global yield trends can be broadly divided into four types (Fig. 1). First, 'yields never improved'-areas that have witnessed no significant yield improvements to date (Fig. 1a). Second, 'yields stagnated'-areas where yields previously improved, but now are stagnating or declining (Fig. 1b). This category includes a range of yield trends post a year of yield maximum, including yields hovering near the yield maximum (that is, a yield plateau) and yield declines at various rates. Third, 'yields collapsed'-areas where yields decreased since the 1960s, or initially increased and then collapsed to the 1960s level (Fig. 1c). Fourth, 'yields still increasing' - areas where yields are still increasing (Fig. 1d). Based on recent rates of yield improvement, we can further divide this category into the top 25\% of yield-improving regions-'yields increasing rapidly'; the bottom $25 \%$ of yield-improving regions'yields increasing slowly'; and the intermediate $50 \%$ of yieldimproving regions-'yields increasing moderately'.

Overall, our analysis shows that most of the world has historically experienced significant yield improvements (Fig. 2, Table 1). The percentage of the world that never experienced any maize, rice, wheat or soybean yield improvement is small $(\sim 1 \%$ of each harvested crop areas; Table 1).

We find that the world's maize, rice, wheat and soybean crops are continuing to experience yield increases in over 70, 63, 61 and $76 \%$ of their harvested areas, respectively-corresponding to 103 , 96, 130 and 63 million hectares (m. ha) (Fig. 2; Table 1). Globally, however, rice $(35 \%)$ and wheat $(37 \%)$ have substantial areas that are now witnessing yield stagnation. Maize (26\%) and soybean (23\%) have less area in yield stagnation. Furthermore, we find that $3 \%$ of maize, $1 \%$ rice and $1 \%$ of wheat areas have experienced yield collapse.

Areas where yields are still increasing currently contribute roughly $79 \%, 57 \%, 56 \%$ and $82 \%$ of the total global production in maize, rice, wheat and soybean, respectively. The remainder comes primarily from regions witnessing yield stagnation. This then means that for wheat and rice, at least, yield stagnation may have profound implications on the ability of agriculture to meet the growing global demands for these commodities.

Below, we explore in more details the major regional patterns for these four crops. For statistical modelling used, model fits and classification used to determine yield trend category, please refer to the (Supplementary Note 1, Supplementary Methods and Supplementary Figs S3-S5).

Regional summaries. Only $\sim 1 \%$ of global maize areas never saw yield increases, and the significant areas were in Morocco and parts of India ( $0.4 \mathrm{~m}$. ha) (Fig. 2a). Yields are stagnating in $26 \%$ of maize-harvested areas (Fig. 2a) -in the United States, generally on the fringes (for example, portions of the Great Plains) of the vast US Corn Belt (yields peaked mostly from mid 1990s, Supplementary Fig. S6), more widespread portions in eastern and southern Mexico (yields peaked mostly early 1990s) and in smaller areas of other major Latin American countries. In some parts of Western Europe, maize yield improvements have stagnated, especially, in Spain, Italy and Greece. Africa has a large extent of maize yield stagnation (yields here peaked mostly from the late 1990s). In Asia, in India and China, maize yields have stagnated across $\sim 31$ and $\sim 52 \%$ of the maize-growing areas. Maize yields have collapsed in only $3 \%$ of global areas prominently in Dominican Republic, parts of northeast Brazil, Moldova, Africa (Chad, Rwanda, Angola, Zimbabwe and Lesotho) and South Asia $(0.07$ and $0.2 \mathrm{~m}$. ha in India and Nepal, respectively). Maize yields are still increasing in $70 \%$ of global areas: in the vast United States Corn Belt, western and central Mexico, and most of Brazil and Argentina. Many other European, African and Asian maize areas are also witnessing steady maize yield improvement. The fastest maize yield improvements globally were found in the Corn Belt of the United States ( $37 \%$ of all maize-harvested areas) and in Latin America, especially Argentina (78\% of all maize-harvested areas), and Brazil. There are also some isolated similar fast increasing areas in Portugal, France, Eastern Europe, Turkey, Nigeria, South Africa, Pakistan, India, China, Vietnam and Indonesia. In most of the United States and Western Europe, maize yields are improving at either fast or moderate rates. 

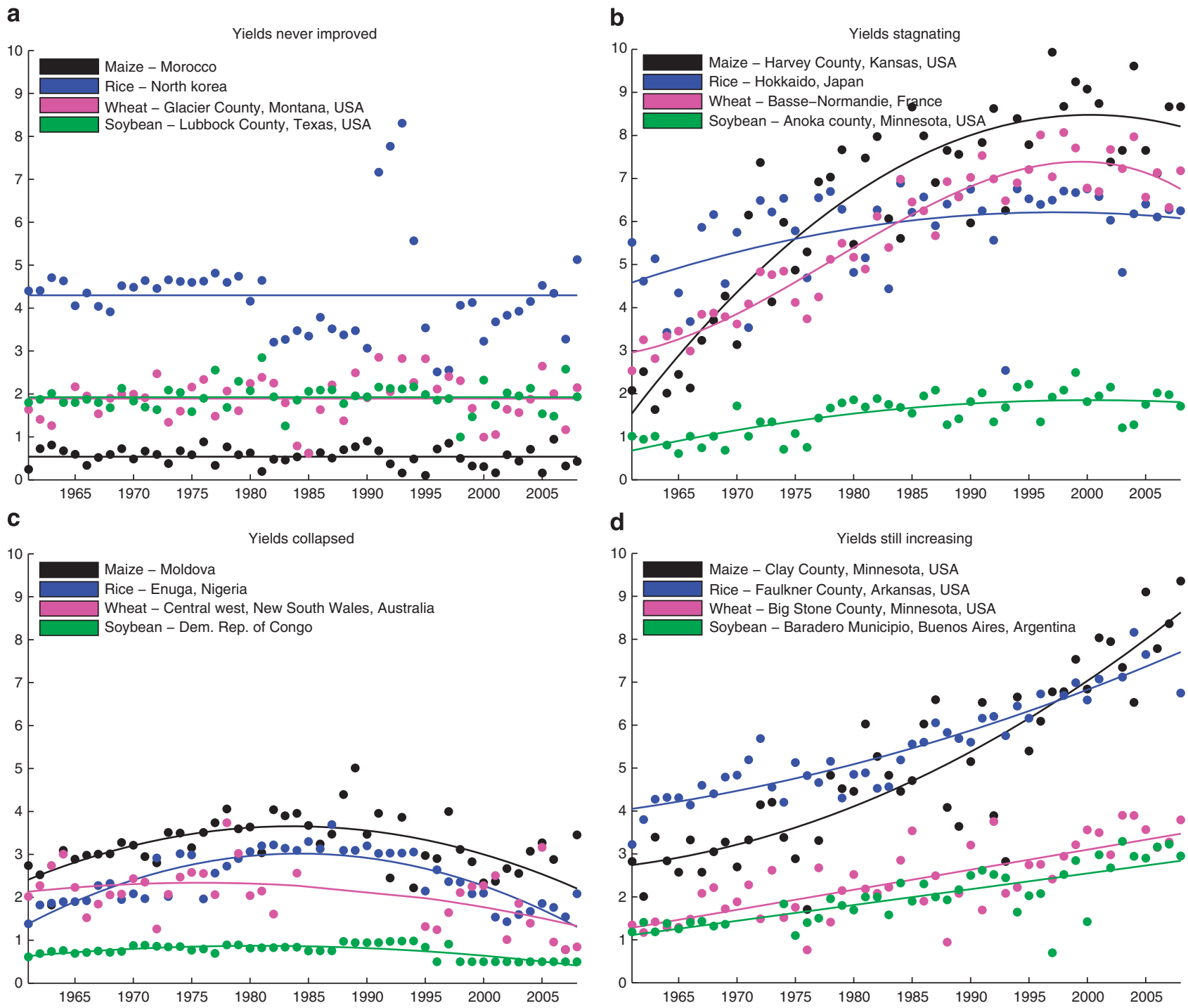

Figure 1 | Illustrative examples for each of the four types of global crop yield trends. The solid filled circles in each panel are the observed crop yields from various global locations to serve as illustrative examples. Colour codes indicate the crop. The solid curves are the statistical model fits to the data and similarly colour coded according to the crop type. (a) Yields never improved. (b) Yields stagnating. (c) Yields collapsed. (d) Yields still increasing.

Only $\sim 1 \%$ of the global rice-growing areas never saw yield increases; these areas were found in parts of Brazil (northeast Brazil), Greece, Mexico and India, as well as in Gabon, Gambia, Democratic Republic of Congo and North Korea (Fig. 2b). Rice yields are stagnating across $35 \%$ of rice-harvested areas globally: in the US state of California (yields peaked here in the late 1990s, Supplementary Fig. S6), parts of Latin America (Fig. 2b), most of Europe and parts of Africa (Fig. 2b). In Asia, the major ricegrowing continent, yields are stagnating in China, India and Indonesia across $79 \%, 36 \%$ and $81 \%$ of rice-growing areas, respectively. Rice yield have collapsed in $1 \%$ of the world's riceharvested areas. The largest areas of rice-yield collapse were in Brazil (northeast Brazil), Sierra Leon and parts of Nigeria in Africa, Iraq and parts of India. Areas with ongoing rice-yield increases are found in all continents in 63\% of global areas (except Australasia). However, large areas of rapidly increasing rice yields are found only in some countries: USA, Colombia, Peru, Argentina, Uruguay, Brazil, Spain, India, China, Vietnam, Afghanistan and Bangladesh.

Wheat yields never improved in $1 \%$ of global areas: in large parts of the United States ( $\sim 9 \%$ of its harvested areas), Argentina
( $\sim 5 \%)$, Peru $(\sim 11 \%)$, Nigeria (100\%), Lesotho (100\%), Mongolia $(\sim 64 \%)$ and parts of Australia ( $\sim 4 \%)$ (Fig. $2 c)$. Wheat yields collapsed in an extremely small fraction of the world $(\sim 1 \%$ globally corresponding to $1.6 \mathrm{~m}$. ha, out of which $\sim 1.5 \mathrm{~m}$. ha was in Australia). Yields are stagnating in $37 \%$ of global areas including $\sim 27 \%$ of wheat areas in the United States (primarily in the Great Plain states where stagnation occurred after peaking mostly in the early to mid 1990s, Supplementary Fig. S6). Furthermore, wheat yields have been stagnating in parts of Argentina ( $\sim 1.8 \mathrm{~m}$. ha or $\sim 34 \%$ of areas since the late $1990 \mathrm{~s}$ ) and almost everywhere in the highly productive wheat-growing areas of Western Europe as well as Eastern Europe. They are also stagnating in Turkey (in $\sim 5.4 \mathrm{~m}$. ha or $\sim 64 \%$ of their wheatgrowing areas), China (56\% of areas) and India (in $\sim 70 \%$ of areas). Wheat yields began stagnating in the Khyber Pakhtunkhwa and Balochistan states of Pakistan (starting after $\sim 2000$ ), and in Australia, wheat yields are stagnating in 44\% of its areas. In all, $61 \%$ of global wheat areas are witnessing yield increases. Most of Canadian wheat areas, 64\% of United States wheat areas, Russian wheat, most African wheat areas, some areas of Asian wheat and $\sim 40 \%$ of Australian wheat areas are still 


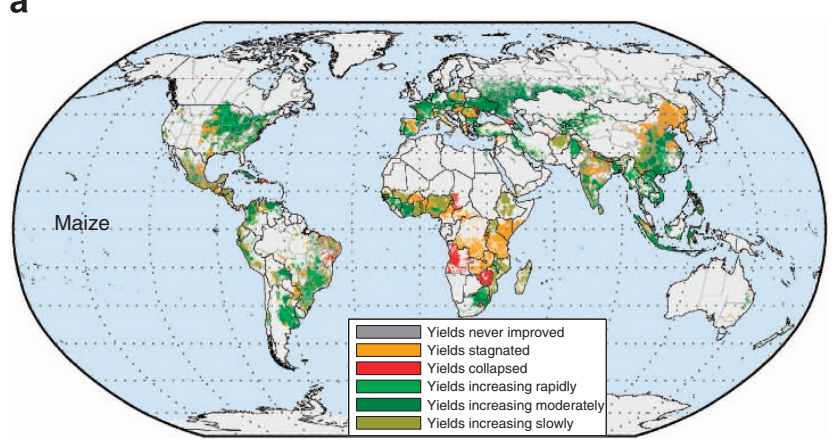

C

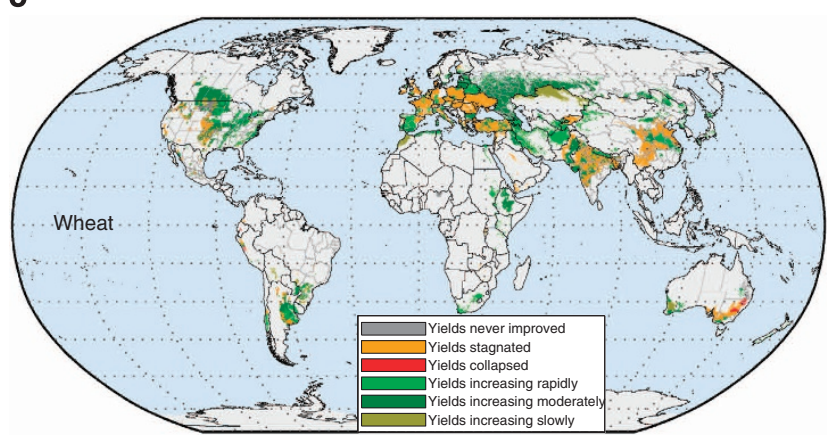

b

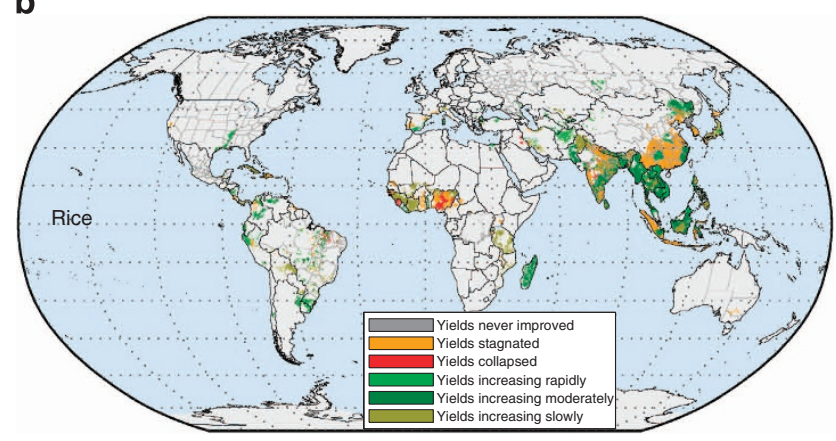

d

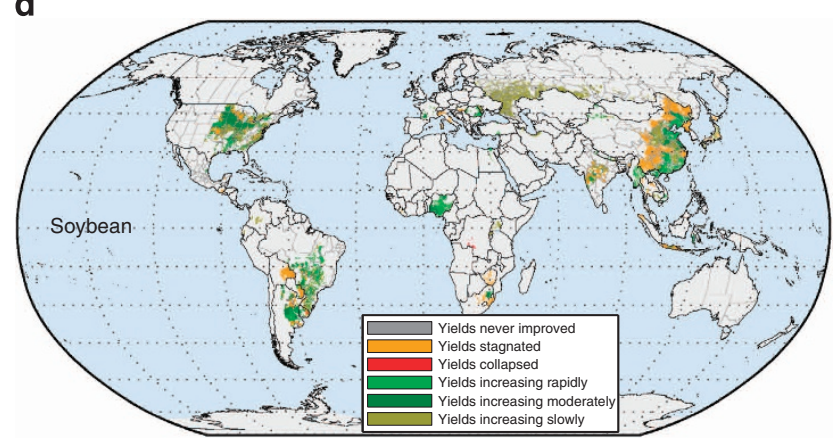

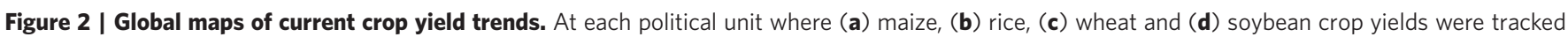
globally, we determined the status of their current yield trend. The trends were divided into the six categories and colour coded. We show in the maps only those areas in the political unit where the crop was harvested.

witnessing yield improvement. Although there are many countries with some fraction of their wheat areas witnessing rapid yield improvement, the countries with the top five spatial extent are (in m. ha): China $(\sim 8)$, Iran $(\sim 4)$, United States $(\sim 4)$, Afghanistan $(\sim 2)$ and India $(\sim 2)$.

Soybean yields never improved in $\sim 0.8 \mathrm{~m}$. ha ( $1 \%$ of all global areas); these areas are concentrated in the United States $(\sim 0.4 \mathrm{~m}$. ha), Argentina, Brazil and Mexico (Fig. 2d). Soybean yields collapsed in an insignificantly small area globally $(0.2 \%$ of global areas). Brazil had a large area of soybean yield collapse $(\sim 0.1 \mathrm{~m}$. ha), as did smaller areas in Uruguay and the Democratic Republic of Congo. Globally, soybean yield stagnation covers $\sim 19 \mathrm{~m}$. ha ( $\sim 23 \%$ of harvested areas), and countries with more than a million ha in yield stagnation are (in decreasing order): China, India, United States, Paraguay, Brazil and Argentina. Yield improvements are also fairly widespread but are more prevalent ( $\sim 76 \%$ of global areas); countries with the largest spatial extent of yield improvements (again listed in decreasing order and more than a million ha each) are: United States, Brazil, Argentina, China and India.

\section{Discussion}

Today, a global food crisis is looming as the world population increases, more people shift towards meat and dairy intensive diets and more cropland is diverted to grow biofuel crops ${ }^{1-4}$. How will we meet these growing demands, especially when recent crop-production trends were insufficient to do so, and many regions are showing significant stagnation and declines in yield improvement?

Looking forward, we must first ensure that areas still increasing yields do not falter, while at the same time improving management practices to reduce impacts on the environment ${ }^{4}$. Next, we have to identify why yield gains for our most important cereal crops are stagnating in more than a quarter of our croplands. Can we reverse the yield stagnation in these areas? At the field to country scale, there are numerous studies showing that both biophysical and socio-economic causes, often not mutually exclusive, are the drivers of these yield changes. The lack of readily available data regarding all possible drivers of global agriculture at the level of our analysis precludes any effort to ascribe the causes behind the observed yield trends. However, below we discuss some of the reported field to country-scale causes of yield changes with an emphasis on Europe, AsiaAustralasia and Africa; these are the continents where yield stagnation appears particularly widespread (Fig. 2).

In the Americas, maize yield stagnation is especially widespread only in Mexico. Here reduced fallow periods in areas of shifting cultivation without concomitant adoption of modern management practices ${ }^{15}$, or non-introduction/adoption of nonlocal but high-yielding maize seeds by farmers ${ }^{16}$, may be responsible. In the United States, greater adoption of no-till practice by farmers in the semi-arid areas of the Great Plains has coincided with intensified crop rotations ${ }^{17}$ (for example, wheatmaize rotations as opposed to a fallow following wheat). Farmer net incomes may have consequently increased, but intensified crop rotations may have also led to increased yield variability and crop failures ${ }^{17}$ in an area of already limited water resources ${ }^{18}$. Our analysis shows widespread yield stagnation in these regions, especially for wheat (Fig. 2a and c).

In Europe, wheat yields may have declined because of climate changes in some countries of Western Europe ${ }^{10}$, though elsewhere in more northern countries, the warmer climate may have led to fewer low yield years, and even expansion of wheat areas $^{14,19}$. Elsewhere in Europe, warmer temperatures may have had no effect on boosting either maize and wheat yields ${ }^{20}$ Confounding the climate-change effects in Europe are socioeconomic and policy decisions to reduce farmer remuneration for 
Table 1 | Yield status globally and for the top 10 producers.

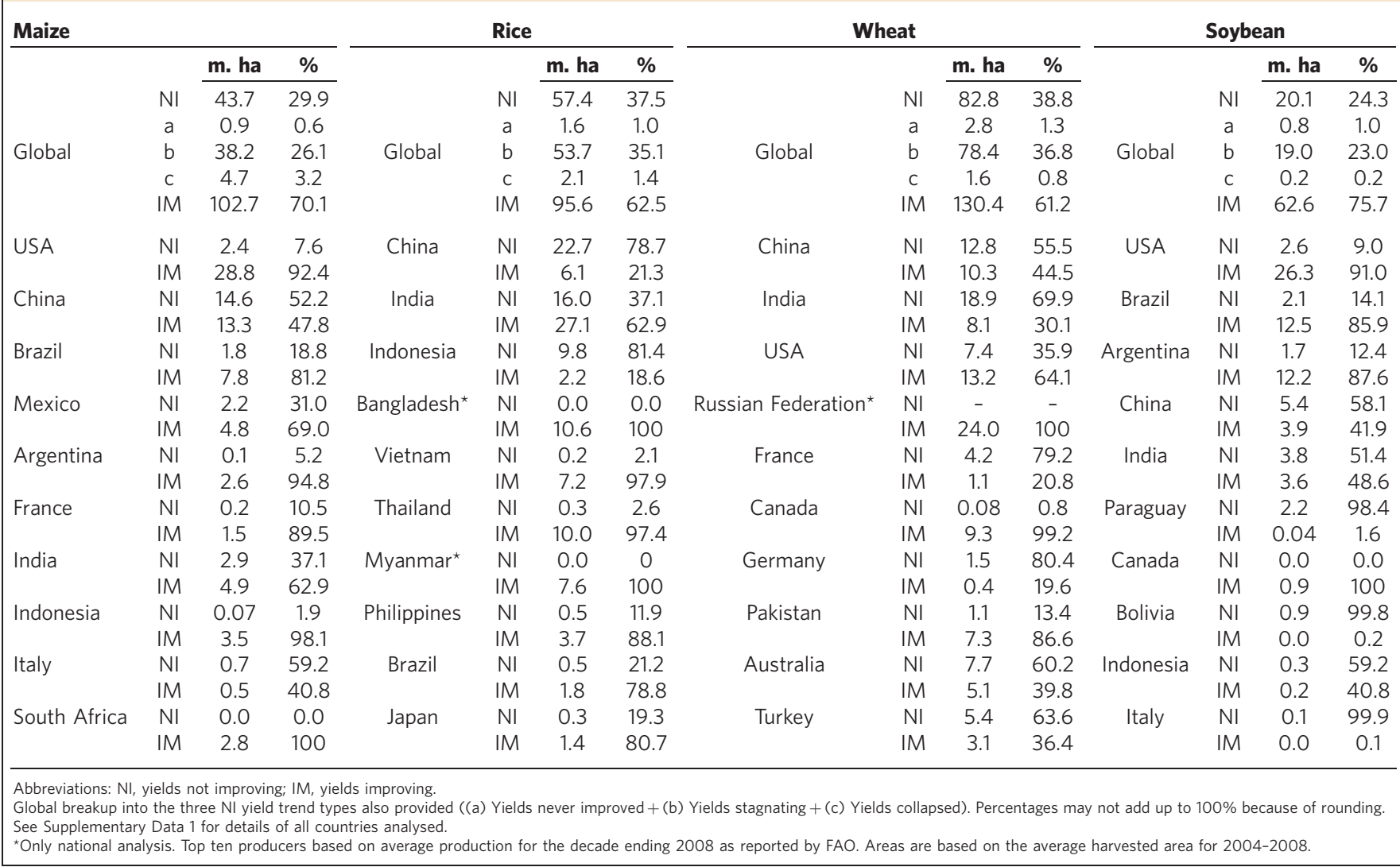

intensive cultivation, or to reduce the environmental burden $6,710,21,22$, which may have reduced farmer inputs leading to yield stagnation ${ }^{11}$ but improved environmental quality ${ }^{23}$. However, there are clearly both regional/country and crop specificities. There may now be fewer incentives to boost wheat yields in Western European countries ${ }^{11}$ (namely in France, Germany and United Kingdom), which correlates with our results showing widespread areas where yield increases have ceased ( $\sim 80 \%$ of the wheat areas in France and Germany, and $~ 99 \%$ in the United Kingdom). However, maize yields are increasing almost everywhere in France and Germany ( $90 \%$ and 100\% of maize-growing areas, respectively). Spain, Portugal and Italy on the other hand have a larger fraction of their wheat areas showing yield increases $(82 \%, 89 \%$, and $76 \%$, respectively) compared with maize $(48 \%, 65 \%$, and $41 \%$, respectively).

In Asia and Australia, yields of wheat and rice may have stagnated as shown in our analysis (see Fig. $2 \mathrm{~b}, \mathrm{c}$ ) due to a combination of factors that are location-specific, including climate-change-related heat stress $^{24,25}$, increased night time temperatures 26 , depletion of soil fertility and salinization ${ }^{12,27}$, soil erosion ${ }^{27}$, increasing competition for water resources ${ }^{28}$, pest and disease build-up ${ }^{27}$ and a lack of capital ${ }^{29}$ to buy more expensive inputs while the real crop prices declined ${ }^{30}$. Wheat yields may have stagnated in Bangladesh ${ }^{31}$, and in parts of India also because of current cultivars approaching their yield potentials ${ }^{32}$. The effect of water scarcity for irrigation, falling groundwater water tables ${ }^{18,27,33}$ and soil-quality depletion may be even more pronounced for rice ${ }^{34,35}$, leading to the widespread rice-yield stagnation (Fig. 2b). The need for new wheat cultivars is another major challenge; specifically, varieties are needed that are heat- and water logging-tolerant for growing conditions in South Asia where wheat follows rice in the crop rotation, and frost- tolerant varieties for the growing conditions in East $\mathrm{Asia}^{27}$ Similarly, rice cultivars that provide high yields in nutrientdeficient soils ${ }^{36}$ are needed to boost yields. Changing the length and type of crop rotation with better management could also boost Asian rice and wheat yields ${ }^{37}$.

In Africa, crop yields may have stagnated due to a complex combination of factors, many of which may ultimately be due to socio-economic limitation. Specific constraints to crop yield increases include variability of dry spells and lack of field-water management strategies in the drier parts of the continent ${ }^{38}$, absence of significant irrigation infrastructure ${ }^{39,40}$, low nutrient application and absence of fallows to restore soil fertility levels ${ }^{41,42}$, lack of availability of suitable high-yielding crop varieties that in turn could be related to institutional and political conditions ${ }^{42-44}$, and the lack of farmer expertise in appropriate agronomic practices ${ }^{42}$. However, when combinations of socioeconomic factors align to overcome the biophysical limitations, significant yields gains are achieved ${ }^{45}$. For example, landscapescale modelling results ${ }^{39}$, field trials ${ }^{46}$ and policy experiments ${ }^{47}$, all demonstrate that fairly small increase in inputs is sufficient to double maize yields in Africa.

Although we have found widespread yield stagnation, an increase in the number of crops per cropping cycle or intercropping with other crops $^{48-50}$ can increase net food supply and farmer incomes ${ }^{17}$. Indeed, global harvested areas have increased at nearly three times the rate of global croplands areas since $1985^{4}$. In some areas, farmers may have prioritized livestock over grain crops, and in other regions, yields may have stagnated, but the total factor productivity (the ratio of the total output to the total input) increased ${ }^{21,51}$. However, globally, there remain many regions where both the growth in yields and total factor productivity of agriculture remain low, perhaps 
because of a lack of established agricultural research and investment ${ }^{51}$.

At the global scale, yields are being affected by both biophysical $^{52,53}$ and socioeconomic ${ }^{22,29,40}$ factors. Differences in crop performance create yield gaps $s^{4,5,32,39}$ that could be overcome by adoption of best management practices ${ }^{54,55,39}$. Understanding how changes to management practices (including fertilizer application, irrigation, pest management and others) could close yield gaps ${ }^{39}$ is critical to addressing stagnating yields on our most important croplands. Failure to identify and alleviate causes of yield stagnation, collapse and never improving yields will have an impact on the future of global food security.

Our global analysis shows that maize, rice, wheat and soybean crops are continuing to experience yield increases in $61-76 \%$ of their global harvested areas. This implies that between $24-39 \%$ of these cropland areas are no longer witnessing yield increases; the spatial extent of such rice and wheat areas is now particularly extensive (37\% and $39 \%$ of global areas, respectively). In all, $43 \%$ of global rice and $44 \%$ of global wheat production are currently from these areas, not witnessing yield increases, raising the important question of how future demands, at least in these two commodities, would be met.

More troubling is our finding that for the top-three global rice producers-China, India and Indonesia, yield gains are not occurring across $79 \%, 37 \%$ and $81 \%$ of their rice cropland areas. China, India and the United States-the top-three wheat producers-similarly are not witnessing yield increases in 56\%, $70 \%$, and $36 \%$ of their wheat cropland areas, respectively. The spatial extent for the top-three global producers of soybean under these yield conditions is much lower, but China, the second largest global maize producer, now has more than half its area not witnessing yield gains (Table 1). China and India, the world's two most populous countries ${ }^{3}$, are now hotspots of yield stagnation with more than a third of their maize, rice, wheat and soybean areas not witnessing yield improvement with the problem being more acute in China. For some crops in these two countries, the spatial extent of yield stagnation is more than half the cropped area.

It is thus quite clear from these results that considerable investment in agriculture is needed in the coming decades to meet the challenges of the growing demand for food; simultaneously, we have to maintain a livable environment ${ }^{4}$. Although this study suggests that we have been losing ground on maintaining growth in agricultural production, there are promising paths to pursue in the years ahead ${ }^{56}$.

\begin{abstract}
Methods
Data development. Our geospatial crop database covers the period between 1961 and 2008 annually, and tracks maize, rice, wheat and soybean performance across $\sim 13,500$ political units (using $\sim 2.5$ million unique harvested area and production statistics from the census bureau/agricultural statistics reporting bodies over this time period). These data were further quality controlled, standardized and converted into yield information at three variable spatial levels based on data availability: national, state and county/district/municípios/departments, geographic units ${ }^{57,58}$. Data availability varied among regions. Missing data values were more common in the early years of the data set. Average values from a 5-year window were then used to interpolate missing sub-national data, constrained by values from the political unit that the data were nested within (see Supplementary Note 1 and Supplementary Methods for further details and maps of data quality).

It should be noted that data quality may be poor in some countries and years, where complete or true information is lacking because of political strife, weak
\end{abstract} institutions, incentives to misreport data, lacking access to proprietary data and so on.

Yield trend analysis. Yield trends were analysed via parsimoniously choosing among regression models of increasing order at each political unit for each crop: an intercept-only model, linear model, quadratic model and a cubic model. We used the Akaike Information Criterion ${ }^{59}$ to decide which model fitted the observed data the best. Next, we conducted F-tests at each political unit to determine the goodness of the model fit against the null hypothesis of a constant model. Model parameters themselves guided the classification of yield trends into the four basic categories. An intercept-only model indicated that 'yields never improved'. If the model chosen was linear with positive slope, it indicated that 'yields were still improving', whereas a linear model with negative slope showed that 'yields collapsed'. Similarly, the sign of the quadratic term when the model chosen is quadratic, and the year of the inflection points when the model chosen is cubic, determined the yield trend category for quadratic and cubic fits. Classification of these models is more complex with details included in Supplementary Note 1 and Supplementary Methods. The statistical fits are appropriate over the observed period, and thus have unknown predictive capacity for future years. Also see Supplementary Tables S2 and S3 for comparisons with other national scale studies and utility of conducting sub-national studies.

Outliers in the data may have influenced model choice in some cases, but it was not possible to remove these data from the analysis, given that it was generally unclear which outliers were real (for example, because of weather fluctuations, pest infestation and so on) and which were erroneous.

\section{References}

1. Godfray, H. C. J. et al. Food security: the challenge of feeding 9 billion people. Science 327, 812-818 (2010).

2. Tilman, D., Balzer, C., Hill, J. \& Befort, B. L. Global food demand and the sustainable intensification of agriculture. Proc. Natl Acad. Sci. USA 108, 20260-20264 (2011).

3. United Nations, Department of Economic and Social Affairs. Population division, population estimates and projections section. http://esa.un.org/unpd/ wpp/index.htm.

4. Foley, J. A. et al. Solutions for a cultivated planet. Nature 478, 337-342 (2011).

5. Cassman, K. G. Ecological intensification of cereal production systems: yield potential, soil quality, and precision agriculture. Proc. Natl Acad. Sci. USA 96, 5952-5959 (1999).

6. Finger, R. Evidence of slowing yield growth-the example of Swiss cereal yields. Food Policy 35, 175-182 (2010).

7. Peltonen-Sainio, P., Jauhiainen, L. \& Laurila, I. P. Cereal yield trends in northern European conditions: changes in yield potential and its realization. Field Crop Res. 110, 85-90 (2009).

8. Hafner, S. Trends in maize, rice, and wheat yields for 188 nations over the past 40 years: a prevalence of linear growth. Agricult. Ecosys. Environ. 97, 275-283 (2003).

9. Kendall, H. \& Pimentel, D. Constraints on the expansion of global food supply. Ambio 23, 198-205 (1994).

10. Brisson, N. et al. Why are wheat yields stagnating in Europe? A comprehensive data analysis for France. Field Crop. Res. 119, 201-212 (2010).

11. Lin, M. \& Huybers, P. Reckoning wheat yield trends. Environ. Res. Lett. 7, 024016 (2012).

12. Ladha, J. K. et al. How extensive are yield declines in long-term rice-wheat experiments in Asia? Field Crop Res. 81, 159-180 (2003).

13. Sacks, J. et al. Monitoring the worlds agriculture. Nature 466, 558-560 (2010).

14. Food and Agriculture Organization of the United Nations (FAOSTAT) http://faostat.fao.org/site/567/default.aspx\#ancor. Accessed on March 2011.

15. Parsons, D. et al. Managing maize production in shifting cultivation milpa systems in Yucatan, through weed control and manure application. Agricult Ecosys. Environ. 133, 123-134 (2009).

16. Dyer, G. A. \& Taylor, J. E. A crop population perspective on maize seed systems in Mexico. Proc. Natl Acad. Sci. USA 105, 470-475 (2008).

17. Hansen, N. C., Allen, B. L., Baumhardt, R. L. \& Lyon, D. J. Research achievements and adoption of no-till, dryland cropping in the semi-arid U.S. Great Plains. Field Crop Res. 132, 196-203 (2012).

18. Gleeson, T., Wada, Y., Bierkens, M. F. P. \& van Beek, L. P. H. Water balance of global aquifers revealed by groundwater footprint. Nature 488, 197-200 (2012).

19. Olesen, J. E. \& Bindi, M. Consequences of climate change for European agricultural productivity, land use and policy. Eur. J. Agron. 16, 239-262 (2002).

20. Chloupek, O., Hrstkova, P. \& Schweigert, P. Yield and its stability, crop diversity, adaptability and response to climate change, weather and fertilisation over 75 years in the Czech Republic in comparison to some European countries. Field Crop Res. 85, 167-190 (2004).

21. Lobell, D. B. The case of the missing wheat. Environ. Res. Lett. 7, 021002 (2012).

22. Barzman, M. \& Dachbrodt-Saaydeh, S. Comparative analysis of pesticide action plans in five European countries. Pest Manag. Sci. 67, 1481-1485 (2011).

23. Glendining, M. J. et al. Is it possible to increase the sustainability of arable and ruminant agriculture by reducing inputs? Agric. Syst. 99, 117-125 (2009).

24. Asseng, S., Foster, I. \& Turner, N. C. The impact of temperature on wheat yields. Global Change Biol. 17, 997-1012 (2011).

25. Lobell, D. B., Sibley, A. \& Ortiz-Monasterio, J. I. Extreme heat effects on wheat senescence in India. Nat. Climate Change 2, 186-189 (2012).

26. Peng, S. et al. Rice yields decline with higher night temperature from global warming. Proc. Natl Acad. Sci. USA 101, 9971-9975 (2004). 
27. Timsina, J. \& Connor, D. J. Productivity and management of rice-wheat cropping systems: issues and challenges. Field Crop Res. 69, 93-132 (2001).

28. Shah, T., Deb-Roy, A., Qureshi, A. S. \& Wang, J. Sustaining Asia's groundwater boom: an overview of issues and evidence. Nat. Resour. Forum 27, 130-141 (2003).

29. Erenstein, O. Resource scarcity gradients and agricultural technologies: scoping implications in the post-green revolution Indo-Gangetic Plains. Outlook Agr. 41, 87-95 (2012).

30. Cassman, K. G. \& Pingali, P. L. Intensification of irrigated rice systems: learning from the past to meet future challenges. GeoJournal 35, 299-305 (1995).

31. Mondal, M. H. Causes of yield gaps and stragies for minimizing the gaps in different crops of Bangladesh. Bangladesh J. Agril. Res 36, 469-476 (2011).

32. Licker, R. et al. Mind the gap: how do climate and agricultural management explain the 'yield gap' of croplands around the world? Global Ecol. Biogeogr. 19, 769-782 (2010)

33. Humphreys, E. et al. Halting the groundwater decline in north-west Indiawhich crop technologies will be winners? Advan. Agron. 109, 155-217 (2010).

34. Khan, S., Tariq, R., Yuanlai, C. \& Blackwell, J. Can irrigation be sustainable? Agricult. Water Manag. 80, 87-99 (2006).

35. Bouman, B. A. M., Feng, L., Tuong, T. P., Lu, G., Wang, H. \& Feng, Y. Exploring options to grow rice using less water in northern China using a modeling approach. II. Quantifying yield, water balance components, and water productivity. Agricult. Water Manag. 88, 23-33 (2007).

36. Gamuyao, R. et al. The protein kinase Pstoll from traditional rice confers tolerance of phosphorus deficiency. Nature 488, 535-539 (2012).

37. Bennet, A. J., Bending, G. D., Chandler, D., Hilton, S. \& Mills, R. Meeting the demand for crop production: the challenge of yield decline in crops grown in short rotations. Biol. Rev. 87, 52-71 (2012).

38. Barron, J., Rockström, J., Gichuki, F. \& Hatibu, N. Dry spell analysis and maize yields for two semi-arid locations in east Africa. Agricult. Forest Meterol. 117, 23-27 (2003).

39. Mueller, N. D. et al. Closing yield gaps: nutrient and water management to boost crop production. Nature 490, 254-257 (2012).

40. Portmann, F. T., Seibert, S. \& Doll, P. MIRCA2000-Global monthly irrigated and rainfed crop areas around the year 2000: a new high-resolution data set for agricultural and hydrological modeling. Global Biogeochem. Cycles 24, GB1011 (2010).

41. Vanlauwe, B. et al. Maize yield as affected by organic inputs and urea in the west African moist savanna. Agronomy J. 93, 1191-1199 (2001).

42. Nziguheba, G. et al. The African green revolution: results from the Millennium villages project. Advan. Agron. 109, 75-115 (2010).

43. Evenson, R. E. \& Gollin, D. Assessing the impact of the green revolution, 1960 to 2000. Science 300, 758-762 (2003).

44. Ejeta, G. African green revolution needn't be a mirage. Science 327, 831-832 (2010).

45. Sanchez, P. A., Denning, G. L. \& Nziguheba, G. The African green revolution moves forward. Food Sec. 1, 37-44 (2009)

46. Twomlow, S. et al. Micro-dosing as a pathway to Africa's green revolution: evidence from broad-scale on-farm trials. Nutr. Cycl. Agroecosyst 88, 3-15 (2010).

47. Sanchez, P. A. Tripling crop yields in tropical Africa. Nat. Geosci. 3, 299-300 (2010)

48. Midmore, D. J. Agronomic modification of resource use and intercrop productivity. Field Crop Res. 34, 357-380 (1993).
49. Li, L. et al. Wheat/maize or wheat/soybean strip intercropping I. Yield advantage and interspecific interactions on nutrients. Field Crop Res. 71, 123-137 (2001).

50. Tsubo, M. \& Walker, S. A model of radiation interception and use by a maizebean intercrop canopy. Agricult. Forest Meteorol. 110, 203-215 (2002).

51. Fuglie, K. O. Is a slowdown in agricultural productivity growth contributing to the rise in commodity prices? Agricult. Econ. 39, 431-441 (2008).

52. Lobell, D. B., Schlenker, W. \& Costa-Roberts, J. Climate trends and global crop production since 1980. Science 333, 616-620 (2011).

53. Cassman, K. G., Dobermann, A., Walters, D. T. \& Yang, H. Meeting cereal demand while protecting natural resources and improving environmental quality. Annu. Rev. Environ. Resour. 28, 315-358 (2003).

54. Trueblood, M. A. \& Arnade, C. Crop yield convergence: how Russia's yield performance has compared to global yield leaders. Comp. Econ. Stud. 43, 59-81 (2001).

55. Liefert, W. M., Gardner, B. \& Serova, E. Allocative efficiency in Russian agriculture: the case of fertilizer and grain. Am. J. Agric. Econ. 85, 1228-1233 (2003).

56. How to feed a hungry world. Nature 466, 531-532 (2010).

57. Ramankutty, N., Evan, A., Monfreda, C. \& Foley, J. A. Farming the planet: 1. Geographic distribution of global agricultural lands in the year 2000. Global Biogeochem. Cycles 22, GB1003 (2008).

58. Monfreda, C., Ramankutty, N. \& Foley, J. A. Farming the planet: 2. Geographic distribution of crop areas, yields, physiological types, and NPP in the year 2000. Global Biogeochem. Cycles 22, GB1022 (2008).

59. Akaike, H. A new look at the statistical model identification. IEEE Trans. Automat. Contr. 19, 716-723 (1974).

\section{Acknowledgements}

We thank the NASA and DOE of the United States, NSERC of Canada and the Gordon and Betty Moore Foundation for their support. N.D.M. was supported with a NSF Graduate Research Fellowship. We also thank George Allez, Laura Bryson and Amy Kimball for their help in collecting and digitizing a portion of the data. This work was also benefitted from the comments of the Foley lab members, as well as editing by Emily Dombeck. We thank James Gerber for helping with Figure 2.

\section{Author contributions}

D.K.R. developed the data with inputs from N.R. D.K.R. led the study design and writing with inputs from J.A.F. D.K.R. conducted the research. N.D.M. and N.R provided suggestions on the study design. N.R., N.D.M. and P.C.W. contributed to writing. J.A.F. and N.D.M. provided suggestions on statistical analysis. All authors discussed the paper and commented on the results.

\section{Additional information}

Supplementary Information accompanies this paper on http://www.nature.com/ naturecommunications

Competing financial interests: The authors declare no competing financial interests.

Reprints and permission information is available online at http://npg.nature.com/ reprintsandpermissions/

How to cite this article: Ray, D.K. et al. Recent patterns of crop yield growth and stagnation. Nat. Commun. 3:1293 doi: 10.1038/ncomms2296 (2012). 